\title{
SCHMIDT, Georg, Geschichte des Alten Reiches. Staat und Nation in der Frühen Neuzeit, 1495-1806
}

\section{Christophe Duhamelle}

\section{OpenEdition \\ Journals}

Édition électronique

URL : http://journals.openedition.org/ifha/1336

DOI : 10.4000/ifha.1336

ISSN : 2198-8943

Éditeur

IFRA - Institut franco-allemand (sciences historiques et sociales)

Référence électronique

Christophe Duhamelle, "SCHMIDT, Georg, Geschichte des Alten Reiches. Staat und Nation in der Frühen Neuzeit, 1495-1806», Revue de l'IFHA [En ligne], Date de recension, mis en ligne le 01 janvier 2000, consulté le 22 septembre 2020. URL : http://journals.openedition.org/ifha/1336 ; DOI : https://doi.org/ 10.4000/ifha.1336

Ce document a été généré automatiquement le 22 septembre 2020.

(C)IFHA 


\title{
SCHMIDT, Georg, Geschichte des Alten Reiches. Staat und Nation in der Frühen Neuzeit, 1495-1806
}

\author{
Christophe Duhamelle
}

1 Les lecteurs de la « librairie allemande » savent combien les études sur l'ancien Empire se sont profondément renouvelées depuis quelques années ; on en trouvera encore la trace dans le présent Bulletin. Il semble que soit venu maintenant le temps des bilans et des synthèses. Le guide d'Helmut Neuhaus (Das Reich in der frühen Neuzeit, 1997 ; BullMHFA, 34, p. 305) est commode, mais succinct. La somme de Karl-Otmar von Aretin (Das alte Reich 1648-1806, 3 vol., 1993-1997 ; BullMHFA, 35, p. 269-271) est magistrale, mais peut décourager le lecteur à la recherche d'une vision plus générale. L'ouvrage de G.S., professeur à l'université d'Iéna dont les travaux sur les comtes d'Empire, entre autres, font autorité, réussit à intégrer le bilan de ces recherches renouvelées en un manuel au sens le plus noble du terme. Trois siècles d'histoire allemande y sont présentés avec précision et clarté. Mais, là où la plupart des manuels précédents enterraient, en 1648 au plus tard, l'Empire et ses institutions en quelques phrases pour mieux se consacrer à la " modernité émergente » des grandes principautés, Prusse et Autriche en tête, G.S. centre constamment son propos sur l'Empire, son évolution, sa vie propre, ses difficultés bien sûr, mais aussi sa capacité à rester jusqu'au bout la référence primordiale pour ceux qui essayaient de penser la nation allemande et pour ceux qui, quotidiennement, éprouvaient les fondements de son ordre juridique. Trois idées directrices guident en effet l'auteur : l'État, dans l'Allemagne moderne, est né avec la mise en place en 1495 de la constitution d'Empire qui reste ensuite le point d'ancrage principal de l'idée nationale ; le caractère étatique est demeuré jusqu'en 1806 complémentaire et partagé : territoires et Empire évoluent en constante interaction et vouloir les séparer revient à ignorer l'originalité majeure de l'histoire politique et institutionnelle de l'Allemagne moderne; la constitution impériale, garante de la propriété, de la diversité et des droits acquis identifiés comme "libertés " s'est profondément inscrite dans les cultures politiques et a joué un rôle majeur dans la définition du « caractère allemand » face aux « despotismes » français ou espagnol. 
2 L'ouvrage reflète aussi les limites de ce renouvellement historiographique. Novateur par ses thèmes, il l'est beaucoup moins par son approche, qui reste essentiellement politique, une tendance que ce livre contribue plus à accentuer qu'à dépasser. Soucieux de réhabiliter l'Empire, il en vient parfois presque à le surestimer et à oublier que si toute l'histoire allemande ne peut être lue à la lumière de 1871, il y eut tout de même 1871. Mais, par son insistance même sur l'idée de Nation, l'ouvrage de G.S. montre que cette relecture de l'histoire moderne est, comme la lecture précédente, non seulement une tentative, sans doute plus nuancée et plus juste, de penser la modernité et l'État des XVIe, XVIIe et XVIIIe s. allemands, mais aussi, plus profondément, le fruit d'un effort toujours recommencé pour apprivoiser un passé complexe, fractionné, problématique et pour lui attribuer une valeur d'héritage. 